\title{
Letrōnica
}

\section{Parafrasear: Por quê? Para quê?}

\author{
Paraphrasing: Why and What for?
}

Onici Claro Flôres ${ }^{1}$

Doutora em Letras pela PUCRS.É professora e pesquisadora na UNISC, onde coordena projeto de pesquisa Consciência linguística e dificuldades de leitura. E-mail: oflores@unisc.br
RESUMO: 0 presente artigo enfoca a paráfrase enquanto um processo linguístico-cognitivo, fundamentando-se em estudos neurocientíficos (DEHAENE, 2012; IZQUIERDO, 2011; VAN DIJK, 2010 etc.). Seu objetivo é, através de uma retrospectiva dos estudos já realizados a respeito do tema, como os de Fuchs $(1982,1985)$ e de outros autores, situar a presente abordagem, destacando a importância da repetição e da paráfrase para a construção do conhecimento. Por fim, sugere que a paráfrase seja reconhecida e valorizada tanto para testar a compreensão leitora quanto para estimular a produção escrita, entre acadêmicos e estudantes dos demais níveis de ensino.

PaLAVRas-chave: Leitura; Paráfrase; Escrita; Ensino

ABSTRACT: This article focuses on paraphrasing as a linguistic-cognitive process, based on neuroscientific studies (DEHAENE, 2012; IZQUIERDO, 2011; VAN DIJK, 2010). The aim is, through a retrospective of studies carried out by Fuchs $(1982,1985)$ and other authors, situate the approach highlighting the importance of repetition and paraphrasing for the knowledge construction. Lastly, it is suggested that paraphrase may be considered for both to test reading comprehension as to stimulate written production, among academic students as well as students of other levels of education.

KEYWORDS: Reading; Paraphrasing; Writing; Teaching 


\section{Introdução}

$\mathrm{N}$ o dia a dia, repetir o que ouve ou lê é algo comum na vida de qualquer pessoa e, também, no cotidiano acadêmico e escolar, tanto que até existe um ditado popular sobre o reconto: Quem conta um conto, aumenta um ponto. Assim, dada a sua frequência e utilidade, parafrasear desempenha papel central na apropriação e conservação do conhecimento e, segundo Fuchs (1985), possivelmente, na sua reformulação, uma vez que se constitui no ponto de articulação entre o que ainda não se sabe (novo) e o que já se sabia (velho). No que tange à leitura, em especial, o texto em leitura é a informação nova a ser processada pela memória de trabalho e, em seguida, registrada e consolidada na memória de longo prazo. Quanto ao conhecimento prévio, o próprio nome já elucida, faz parte da memória de longo prazo do leitor, portanto, é o conhecimento preexistente, velho.

Salienta-se, por outro lado, que a atividade de produzir paráfrases envolve, necessariamente, ativar a memória, porque tanto o processamento da leitura quanto a reprodução do texto lido o exigem. A compreensão, no entanto, não é mobilizada, de modo concomitante à atividade leitora, porque ler não é o mesmo que compreender. Na verdade, ler e compreender não se implicam nem se confundem, não sendo funções intelectuais idênticas. A leitura sem compreensão é, porém, uma atividade cognitiva incompleta, parcial. Por isso é indispensável entender.

Para comprovar a compreensão, um dos testes usados é o da produção de uma paráfrase e para produzi-la, o parafraseador tem de repetir o conteúdo do texto lido com as próprias palavras, reproduzindo as informações, sem copiá-las. Desse modo, repetir o conteúdo do texto lido de forma diferente daquela como foi escrito é a prova do seu entendimento, sobretudo, porque a memória de trabalho não tem condições de processar o texto lido, em sua totalidade, a não ser que seja minúsculo (tendo até, digamos, umas sete palavras) ou o leitor tenha decorado tudo o que o texto contiver; neste caso repetindo-o ipsis litteris. Nesta condição não se trataria mais de uma paráfrase, mas de cópia ou plágio, simplesmente.

De outra parte, compreender um texto e demonstrar que o entendeu implica interpretá-lo, integrando o contexto à sua interpretação. Segundo Dascal (2006, p. 195), contexto é “a informação disponível para uma determinada pessoa, para a interação com um determinado processo, em uma determinada ocasião". Em outras palavras, compreender um texto requer não apenas entender as palavras e as estruturas gramaticais nele contidas, envolvendo também a compreensão dos conhecimentos, dos fatos e das ideias que embasam o seu conteúdo, sem, todavia, o integrarem de maneira explícita (DASCAL, 2006).

Em vista disso, a produção parafrástica tal como aqui é considerada se dá a partir do input - texto lido - que possibilita a criação de uma representação semântica do texto - o texto base - (KINTSCH \& VAN DIJK,1978), o qual se constitui de um conjunto de proposições que encerram o significado textual. $\mathrm{O}$ processo de criação do texto base ocorre paralelamente à ativação na memória de um modelo de situação. Em outras palavras, o processamento textual envolvido na elaboração de uma paráfrase não implica apenas a criação de uma representação mental da base textual na memória, mas ainda a ativação, atualização e outros usos do assim chamado modelo situacional na memória episódica (VAN DIJK, 2010).

Assim, a memória episódica contém a representação subjetiva do texto e inclui o evento como um todo - o modelo situacional -, relacionando-se às construções pessoais, às inferências e às experiências anteriores do sujeito. Para construir esse modelo, o parafraseador se baseia em outros modelos de contexto para poder recontar, e a atividade envolve a opção pelo gênero e tipo textual requerido, a seleção lexical, a estrutura das frases, a ênfase etc. 
Em decorrência, parafrasear é uma ação cognitiva relevante porque requer repetição, e repetir é aprender (IZQUIERDO, 2011), mas não se limita a isso. Implica, ainda, alterar o texto, recontando-o, sem copiá-lo. Por isso mesmo, um dos recursos mais efetivos na produção de paráfrases é o emprego da sinonímia ou equivalência de sentido, que não se manifesta apenas no plano lexical. "É fenômeno encontradiço no plano sintático, [...] embora aí entrem em jogo aspectos peculiares, que singularizam a sinonímia sintática da léxica" (DUARTE, 2003 p. 242).

No entanto, é importante frisar com insistência que parafrasear não se restringe, necessariamente, a fazer mudanças sintáticas e semânticas mínimas, de modo usual, elencadas em estudos concernentes ao tema (Ver PERINI, 1995; ILARI e GERALDI, 1990), exigindo também articular ideias, relacionando-as ao contexto em que foram produzidas e, também, ao contexto histórico do leitor. Dessa forma, ainda que a atividade de parafrasear, em si mesma, não se proponha a alterar o conhecimento, antes a reproduzi-lo (ARIMATÉIA e CAMPOS, 2011), a paráfrase desencadeia alterações no que foi lido, acarretando um afastamento progressivo entre texto lido e texto parafraseado.

A necessidade de recontar leva o parafraseador a elaborar sua própria versão textual. Não lhe basta repetir, até porque para repetir tal qual ele teria de decorar. Sua pretensão é a de mesmo mantendo-se fiel ao lido, reproduzi-lo à sua maneira. Porém, como já ressaltou Austin (1990) dizer é fazer, e por isso ao usar sinônimos/hiperônimos/hipônimos, fazer jogos de palavras e/ou alterar a organização/distribuição das informações, o parafraseador promove deslocamentos informativos, elabora maneiras de dizer alternativas e, por vezes, também, desencadeia mudanças no seu próprio modo de entendimento do real, pois as palavras podem alterar o curso do seu pensamento, direcionando-o de modo distinto e até mesmo inusitado (VYGOTSKY, 1987, 1988).
Daí que a parafrasagem não é uma atividade linguístico-cognitiva irrelevante, inócua, podendo dar lugar a ideias novas e nuanças de significado ignoradas até o momento da produção parafrástica; pode, ainda, desvelar implícitos textuais; revelar omissões anteriores; eliminar ou acrescentar informações; propor analogias pouco comuns e, uma vez que promove o deslocamento das palavras de seus lugares usuais, fixos, levar a que os vínculos mais engessados entre palavras e estruturas se rompam, propiciando que o parafraseador reproduza o texto lido de modo distinto e até mesmo lhe confira novos horizontes interpretativos.

Nessa ótica, o texto parafraseado constitui-se num material disponível para investigar como o conhecimento é construído, evidenciando de modo congruente a intersecção entre linguagem, cognição e cultura. Por isso mesmo, a análise de paráfrases é relevante, quando se pretende considerar o modo como se processa o ensino-aprendizagem a partir daquilo que é escrito pelos estudantes, porque o recurso à retomada do já dito é constante tanto na fala quanto na escrita, para os mais diversos fins. Na prática, parafrasear é reativar um texto anterior com alguma modificação formal, e por meio da paráfrase produzida o conhecimento anterior, ou seja, o texto fonte é relembrado e recuperado através de outro que lhe é posterior. 0 tempo cronológico é, sem dúvida, um dos fundamentos da distinção entre texto lido e texto parafraseado, o qual se diferencia do seu antecessor, muito ou pouco, de acordo com os propósitos do parafraseador, que pode almejar apenas repetir o que leu ou introduzir as ideias nele contidas num texto próprio.

\section{Os vínculos entre memória e escrita}

Memória e linguagem se interconectam e se realimentam, de maneira contínua, incessante, porque são funções cognitivas interdependentes, não havendo como desligá-las. Desse modo, caso se considere o processo de 
leitura de modo restrito, o que é lido, usualmente, é o texto escrito, sendo reconhecido, nesse caso, o saber do senso comum, que entende que as pessoas leem o que está escrito em uma dada língua. De outra parte, há que considerar que um dos procedimentos didáticos mais comuns entre os professores do ensino básico é o de pedir que os alunos escrevam a respeito de determinado tema, a partir da leitura de um texto, por eles selecionado (pelos professores). A atividade de escrita exige, então, algum input, que de hábito é o texto impresso, distribuído para leitura antes da realização da atividade de escrita. Essas observações óbvias e bastante triviais comprovam, entretanto, a adequação das palavras de Bakhtin (2000) sobre a dialogicidade da linguagem.

Para ler, a mobilização cerebral inicia-se pelos olhos, que fixam o material a ser lido e repassam as informações para a memória. A memória de que se fala aqui é a memória de trabalho, encarregada do processamento da atividade leitora, gerenciando-a através do retentor episódico (episodic buffer) que interliga a leitura on-line à memória de longo prazo do leitor, ativando-a. Essa ativação permite relacionar informações novas (texto em leitura) com informações preexistentes no cérebro (conhecimento enciclopédico), para o que ambas - tanto MT (memória de trabalho) quanto memória de LT (longo prazo) - são requeridas.

Por outro lado, para produzir uma paráfrase a(s) memória(s) tem(têm) de ser mobilizada(s), sendo ela(s)não só importante(s), mas indispensável(eis) para a execução da tarefa. Em decorrência, a leitura, e mais ainda a escrita, são atividades que, de início, ativam o cérebro do indivíduo, sendo tais atividades praticadas, isoladamente. Ainda que realizadas pelo indivíduo, que precisa que o seu cérebro responda às demandas exigidas por uma e outra, o estudo, a reflexão ou a emoção estética experimentada na leitura de um livro ou na apreciação de uma dada música, por exemplo, podem ser transmitidas e compartilhadas com outras pessoas através da linguagem verbal (falada ou escrita) - dentre outras possibilidades. Então, a dialogicidade é buscada nessas atividades - após a tarefa de leitura/escrita e não antes dela, pois o diálogo propiciado é o output desejado. Desse modo, a escrita assim como a leitura, de modo geral, também é uma atividade individual isolada, mesmo quando o texto resultante é elaborado em dupla ou em grupo, como em situações em que se redige um abaixo-assinado, uma petição coletiva etc. Em tais circunstâncias, alguém se encarrega da formulação, enquanto outros pensam na divulgação, na circulação e assim por diante.

Na escola e, também, nos primeiros anos do ensino superior, pelo menos no Brasil, cada estudante aprende a ler e escrever acompanhado e guiado pelo professor ou professora, porque esta aprendizagem não é espontânea, ela faz-se no quadro de uma relação social em que aluno (a) e professor(a) desempenham papéis diferentes. Ambos compartilham, de início, a situação de leitura e de escrita, até que o leitor (redator) ganhe autonomia para fazêlo por sua conta e risco. Tradicionalmente, esta situação dual ou grupal de leitura começa com a entrada da criança na escola. Em muitos grupos sociais, até hoje, não é comum os pais envolverem-se no ensino da leitura e da escrita, antes de a criança ter idade para frequentar o ensino formal (no Brasil, a partir dos 6 anos). Contudo, a crescente importância que os pais atribuem ao domínio seguro e precoce das funções cognitivas implicadas na leitura, associada aos possíveis benefícios de sua participação mais efetiva na educação dos filhos, tem feito com que se multipliquem as situações em que eles se dispõem a compartilhar situações de leitura com seus filhos, tentando ajudá-los a progredir em seus estudos.

Quanto à memória, Sternberg (2000, p. 204) afirma que ela é "o meio pelo qual você recorre às suas experiências passadas a fim de usar essas informações no presente; refere-se a um processo de mecanismos dinâmicos associados à retenção e recuperação da informação". Essa definição dá uma ideia aproximada da importância da memória para a atividade de 
leitura/escrita na vida diária. Talvez tal importância possa ser subestimada por despreocupação ou desinteresse pelo assunto, digamos, porém há que considerar que sem a memória perde-se, inclusive a possibilidade de encadear a escrita de um texto de tamanho mínimo. De fato, a memória contribui decisivamente para a escrita, porque escrever exige consciência o tempo todo. Mesmo a manutenção do interesse em escrever sobre determinado tema envolve conseguir reter a motivação, o objetivo da atividade de escrita ao longo da produção do texto, caso contrário ela se extingue e a atividade perde a razão de ser. Consequentemente, quando a memória falha, a pessoa enfrenta dificuldades de variada ordem, entre elas a de pensar com coerência sobre um tema e desenvolvê-lo com congruência. Em vista disso, o estudo de embaraços e transtornos decorrentes de problemas ou erros da memória é relevante não só para a leitura, mas também para a escrita, que é uma atividade que requer consciência e monitoramento ao longo de todo o processo de produção textual da paráfrase, que é a produção escrita considerada no presente artigo.

\section{Que aspectos específicos devem ser considerados ao se analisar paráfrases?}

Segundo Fuchs (1982), a paráfrase não pode ser considerada apenas em termos linguísticos, de modo estrito, não se circunscrevendo a estabelecer equivalência sintático-semântica, ou seja, essa autora descarta de imediato o mero recurso ao critério de correspondência. Em seguida, ela enumera quatro planos possíveis na produção e análise de paráfrases: o locutivo, o referencial, o pragmático e o simbólico.

Quanto ao plano locutivo, Fuchs (1982) afirma que ele se funda na língua, enquanto sistema, naquilo que é equivalente, semanticamente, do ponto de vista formal, nele se destacando o papel da correspondência entre formas. Os estudos dessa natureza focalizam a sinonímia lexical e semântica, como já discutido por diversos autores (PERINI, 1995). Nessa perspectiva, a paráfrase relaciona-se à função metalinguística e o parafraseador utiliza a linguagem para reproduzir o texto lido, segundo seu modo de entendê-lo, substituindo palavras ou alterando estruturas frasais determinadas.

O plano referencial, de outra parte, demanda levar em conta a enunciação, que envolve "[...] as operações (intimamente ligadas às operações predicativas) através das quais o sujeito atribui ao enunciado certo número de valores referenciais (de tempo, de aspecto, de modalidades, de determinação, etc.)", ancorando o enunciado na situação comunicativa ('eu-aqui-agora') (FUCHS, 1982, p. 129). ${ }^{1}$

Dessa forma, o plano referencial se reporta à identidade das referências feitas textualmente, envolvendo a situação comunicativa e não somente a estrutura sintático-semântica. Em tais circunstâncias, evidentemente, entram em jogo fatores que ultrapassam a superposição de formas. É necessário haver conhecimento compartilhado entre os interlocutores a respeito das identidades referenciais presentes, textualmente. Se a identidade referencial não for reconhecida, a comunicação fica prejudicada e a intercompreensão não se efetiva.

No plano pragmático, a produção parafrástica relaciona-se às intenções do parafraseador. Quem é ele, a quem se dirige, para que e de que forma? Consequentemente, nesse tipo de produção parafrástica, além da referência, do espaço e do tempo, são considerados os participantes da situação comunicativa, mediados pela linguagem, que não é vista como à parte, uma estrutura independente e alheia àqueles que a produzem e a interpretam, mas como uso contextualizado dos recursos disponíveis.

${ }^{1}$ [...] les opérations (intimement liées aux operations prédicatives) par lesquelles le sujet assigne a l'énoncé un certain nombre de valeurs (à son 'moi-icimaintenant') (FUCHS, 1982 p. 129). 
Em nível pragmático, a produção de paráfrases em sala de aula enseja considerar, inclusive, a forma fonética do texto parafraseado, pois mesmo entre acadêmicos de letras é perceptível a influência da fala no texto produzido por escrito e a inadequação ou não da linguagem textual aos fins tidos em vista (aspecto locucionário); a recepção positiva ou não do texto pelos colegas e o valor assumido por ele tal como escrito - ele impressionou pelo modo de dar explicações, ele se alongou demais, não foi claro e por isso não convenceu e assim por diante; ou seja, o que um dado aluno fez pelo fato de dizer algo da forma como disse (aspecto ilocucionário). Por fim, não dá para desconsiderar o efeito produzido pelo texto nos sentimentos, pensamentos e ações dos leitores, do próprio parafraseador ou de outras pessoas envolvidas, como o professor. $\mathrm{O}$ texto foi convincente, foi ignorado ou criticado por ser uma mera cópia. Trouxe aspectos novos para a discussão e análise posterior das produções? O que, de fato, a paráfrase feita ocasionou no comportamento do parafraseador e dos leitores? $\mathrm{O}$ ato perlocucionário resulta de ter sido dito algo que não é convencional, não consistindo em outro ato do dizer e não podendo ser explicitado (aspecto perlocucionário).

Segundo Duarte (2003, p. 249), o plano simbólico embasa-se "nas figuras de estilo e nos gêneros literários". O autor destaca dentre as figuras de estilo presentes nesses tipos de paráfrase metáfora e alegoria, citando textos bíblicos e literários para exemplificar seu ponto de vista. Quanto à metáfora, a questão tal como enfocada por Duarte é polêmica, pois, em primeiro lugar, a metáfora não se manifesta somente em textos literários, mas também na linguagem do dia a dia; além do mais ela não é apenas um adereço da linguagem, sendo o pensamento também metafórico (LAKOFF e JOHNSON, 2002).

Enfim, no que diz respeito ao presente estudo, o que merece destaque é que a produção parafrástica nesse plano remete à transformação genérica do texto base, que é o ponto que se quer enfatizar aqui. Sobre esse tipo de parafrasagem podem ser citados vários exemplos de experiências, em sala de aula, em que o professor - sobretudo, do Ensino Básico, solicita que os alunos façam paródias de músicas ou poemas, havendo, ainda, bons exemplos de textos literários e, mesmo, de histórias infantis já parodiadas. Além desses exemplos, há outros em que o professor pede aos alunos que transformem uma HQ em uma narrativa, sem recorrer aos desenhos (linguagem icônica), e assim por diante.

\subsection{Caracterização da paráfrase enquanto produção textual}

Em A paráfrase Linguística, Fuchs (1985) fez uma retrospectiva do uso do termo que, de acordo com ela, ressurgiu em meados dos anos 60, em função de três tipos de pesquisa linguística frequentes à época: tratamento automático de textos (Harris); relações entre frases, na perspectiva gerativotransformacionalista, e ampliação do objeto de estudo da semântica (da palavra para o texto). Antes disso, falava-se exclusivamente em resumo. Por resumo entendia-se e entende-se até hoje a reprodução de um texto com extrema fidelidade às ideias e às palavras nele constantes.

O uso do termo resumo remete a uma concepção de linguagem centrada na fidelidade ao dito anterior, ancorando-se numa visão de língua escrita, enquanto objeto sacralizado. Por isso, talvez, no senso comum, resumir seja entendido meramente como abreviar. Tal entendimento manifesta-se, hoje em dia, em atitudes bastante comuns, comuns até demais! Alunos do Ensino Básico costumam resumir textos da seguinte forma - copiam ou recortam uma ou duas frases do início do texto, algumas outras do meio (desenvolvimento) e acrescentam a conclusão. Pronto, o resumo está feito. Não há o que discutir ou entender, basta reproduzir o que estava escrito no texto lido.

O uso do vocábulo paráfrase, porém, enseja estranhamento, porque mesmo que circule desde os anos 60 , muitos professores e acadêmicos o 
desconhecem. Fuchs comenta que o termo ressurgiu em meio a grandes transformações nos estudos linguísticos, testemunhando a emergência de novas formas de entendimento da linguagem. Em vista disso, o conceito de paráfrase é mais versátil e elástico. Em certo sentido, no entanto, resumo e paráfrase são termos considerados equivalentes. Ambos implicam reproduzir. Por isso mesmo, Fuchs ressalta que a noção de paráfrase é difícil de explicitar, "tanto na teoria quanto na prática". De acordo com ela, a paráfrase pode ser caracterizada como:

[...] um dado imediato da consciência linguística dos locutores (saber uma língua é poder produzir e identificar frases como 'tendo o mesmo sentido'), mas é também o produto das construções teóricas dos linguistas (o número e a natureza das paráfrases descritas é função direta do modelo de referência); - uma atividade linguística dos sujeitos (um trabalho de interpretação e de reformulação), mas é também o objeto resultante desta atividade (o enunciado ou o texto que reformula o outro); - uma relação entre um enunciado ou textofonte e sua(s) reformulação(ões) efetiva(s) numa situação dada (dimensão 'sintagmática' da cadeia do discurso), mas é também uma relação entre todos os enunciados virtualmente equivalentes na língua ('dimensão paradigmática' do sistema da língua) (FUCHS, 1985, p. 129).

Em seu estudo a respeito, a autora elencou as seguintes abordagens teóricas da paráfrase: 1) a lógica (equivalência formal); 2) a gramatical (sinonímia) e 3) a retórica (reformulação). A perspectiva lógica postula que duas proposições são equivalentes, se e somente se tiverem o mesmo valor de verdade. Contudo, ressalta Fuchs, a noção de valor de verdade não é de fácil aplicação aos enunciados linguísticos que acabam fugindo aos estritos limites da lógica formal. Quanto ao ponto de vista gramatical, a correspondência de sentido diz respeito a relações entre palavras (sinonímia, por exemplo) e entre tipos frasais: frases ativas versus passivas, dentre outros. Por fim, a abordagem retórica, diz a autora, discute a paráfrase no plano do discurso, "como uma atividade efetiva de reformulação pela qual o locutor restaura (bem ou mal, na totalidade ou em parte, fielmente ou não) o conteúdo de um texto fonte sob a forma de um texto segundo" (FUCHS, 1985 p. 130).

Neste estudo, todavia, focaliza-se o processo de reconstituição textual propiciado pela produção parafrástica em termos linguístico-cognitivos, não se pautando ele, de modo exclusivo, pelas abordagens elencadas por Fuchs: lógica, gramatical ou retórica, apesar de integrá-las à análise proposta. Além disso, retoma três das quatro dimensões citadas pela autora - a locutiva, a referencial e a pragmática, deixando de lado a paráfrase simbólica. Na perspectiva assumida, considera-se que a reformulação parafrástica manipula a língua (princípios de funcionamento), e, ao fazê-lo, incorpora princípios cognitivos, já que não existe, na verdade, independência total da linguagem em relação à cognição. Saeed (1997, p. 301), inclusive, assegura que "[...] não temos acesso à realidade independente da categorização humana e por isso a estrutura da realidade tal como refletida na língua é um produto da mente humana".

Em vista disso, postula-se que a parafrasagem é, não só necessária, mas indispensável para garantir o estabelecimento do significado. Esse significado não é, no entanto, fixo, estático, apesar de ser a base conceitual comum, que permite a elaboração mental intersubjetiva, vinculada a situações concretas, negociadas de modo colaborativo ou conflitivo, em cada situação interativa específica. Para a reformulação parafrástica, entretanto, é preciso haver "uma interpretação prévia do texto-fonte, de maneira que se restaure o texto de modo diferente" (FUCHS, 1985, p. 130).

\subsection{Etapas do processo de produção parafrástica}

A produção de paráfrases envolve três etapas distintas, segundo a proposta de Fuchs (1985): leitura, interpretação e (re)produção textual e focaliza a (re)construção do conhecimento através de textos, não de conceitos isolados nem de frases, com o que se concorda. Nesse enfoque, manutenção 
e/ou aprimoramento do conhecimento ocorre(m) através de textos e neles cada conceito, cada palavra, cada frase, faz parte de uma estrutura complexa - um modelo cognitivo global - que constitui o modo de entendimento do que seja o mundo para um determinado grupo de indivíduos, de vez que, de acordo com van Dijk (2012 p. 259), “[...] adquirimos a maior parte do nosso conhecimento por meio de textos e de interlocuções [...]”.

Os estudos de leitura, no entanto, avaliam paráfrase e repetição com bastante restrição, sendo a reprodução fiel considerada falta de horizonte e a paráfrase como horizonte compreensivo mínimo. Claro está que não é possível contestar que a repetição pura e simples não gera evolução do conhecimento. Até porque, nesses casos, diz Marcuschi (2007), o leitor age como se fosse detentor de um saber indiscutível, como se a linguagem fosse espelho da realidade e da verdade. O que é "um mito, uma quimera" (MARCUSCHI, 1996, p. 75).

Evidentemente, a paráfrase pode ser tão similar ao texto original, que com ele quase se confunda. Marcuschi, inclusive, define a leitura parafrástica como "uma espécie de repetição com outras palavras em que podemos deixar algo de lado, selecionar o que dizer e escolher o léxico que nos interessa" (MARCUSCHI 1996, p. 75). A ponderação de Marcuschi é relevante. Mas a questão remanescente é: Será que repetir não tem qualquer função na construção do conhecimento? Repetir é insuficiente, não resta dúvida, mas o papel cognitivo da repetição será dispensável ou inexistente? E, mais ainda, parafrasear será uma atividade linguística sem função cognitiva?

Os questionamentos interpostos no parágrafo anterior se fundamentam em estudos neurocientíficos (DEHAENE, 2012; GAZZANIGA, 2002) e podem ser resumidos na pergunta: como construir conhecimento sem considerar as características e os limites do cérebro? A ressalva relaciona-se à memória humana. Alguém pode alegar que algo repetido é algo já sabido, já memorizado, e que a repetição não é suficiente para atestar que houve compreensão. É preciso pensar, raciocinar. De fato. Contudo, há que reconhecer, repetir o que se sabe é uma etapa necessária, indispensável para a aprendizagem. Sem repetir o já sabido e testado, como formular novas hipóteses investigativas? Como fornecer um output, sem input anterior?

Em vista disso, na perspectiva aqui apresentada, repetir parece ser o passo inicial, indispensável, para o registro e manutenção do conhecimento, e, mais ainda, para a estabilização desse conhecimento entre os membros de uma dada área ou campo do saber. Subestimar a importância de repetição para a construção intersubjetiva do conhecimento não se justifica, se considerada a importância dos estudos neurocientíficos para entender como vive e age o indivíduo humano em sociedade.

Por outro lado, sem parafrasear, a alteração ou variação no modo de formular o conhecimento torna-se inviável. Como saber se algo foi aprendido? É preciso dizer com as próprias palavras o que se compreendeu a fim de demonstrar compreensão. Pequenas mudanças de palavras e combinações de palavras introduzem ideias novas, novas associações, lembranças relacionadas ao fato, reconhecimento de similaridades e outras formas de conceber o problema, reunindo informações do texto e do contexto.

Assim, negar a importância da repetição e da parafrasagem indica pouca familiaridade com a interdependência existente entre cérebro (corpo), cognição (pensamento) e linguagem. Isso porque, se eliminados esses dois modos de (re)produção do sabido - repetição e paráfrase -, a humanidade estaria sempre voltando à invenção da roda, no que se refere ao processo global de construção do conhecimento.

Para investigar a paráfrase é imprescindível, então, considerar essa interdependência, levando em conta a natureza humana, suas possibilidades e limitações, não ignorando, além disso, que o conhecimento é construído em certo lugar e tempo, por certos indivíduos - saber local, instrumentos e ferramentas fazem parte do processo e do produto construído. Em suma, 
o indivíduo humano tanto depende da biologia quanto da cultura para ser aquilo que é.

Negar ou diminuir a importância da repetição e da paráfrase, enquanto fundamento da construção do conhecimento é inconsequente, inclusive porque, do ponto de vista histórico, constata-se um mesmo movimento com relação a todo tipo de atividade cognoscitiva humana. A repetição do conhecimento construído é uma forma de preservação daquilo que a humanidade atingiu até determinada etapa evolutiva; o movimento seguinte é o da diferenciação, a partir de acréscimos e modificações parafrásticas. Sobre o assunto diz Sinha (2005, p. 331) o seguinte:

[...] o nível sociocultural emerge do biológico, sendo dele relativamente autônomo (mas atuando retroativamente por "captura") o nível "psicológico" (que não emerge autonomamente do nível biológico). Nesse sentido, não há "Mente/Cérebro", desde que "a mente" é coconstituída pelo biológico e pelo social (SINHA, 2005, p. 331). ${ }^{2}$

\section{Paráfrase \& categorização}

Por outro lado, como evoluir sem correr o risco de regressão? Ou seja, como garantir que o conhecimento não se dissipe e prossiga evoluindo? Quanto a essa questão, um conceito importante é o de efeito catraca, proposto por Tomasello (2003). Esse autor afirma que para garantir que não haja retrocesso evolutivo o conhecimento alcançado tem de ser mantido num dado patamar e para que isso aconteça, afirma ele, atua a catraca, ou retomada desse conhecimento, sua repetição e reprodução por toda a espécie.

\footnotetext{
$2[\ldots]$ the socio-cultural level is emergent from the Biological one, relatively autonomously from (but acting back upon by "capturing") the "psychological" level (which is non- autonomously emergent from the biological level). In this view, there is no "Mind/Brain", since "mind" is coconstituted by the biological and social (SINHA, 2005, p. 331).
}

Assim, a evidência mais clara da dissociação, ainda, existente entre estudos sobre leitura e paráfrase daqueles sobre o cérebro (neurociências) traduz-se na desconsideração ao modo de conhecer humano e explica, até certo ponto, a pouca valia atribuída à função da repetição (registro na memória de Longo Prazo) para a construção do conhecimento, pois ignorar a importância dos aspectos biológicos do cérebro inviabiliza discutir leitura e paráfrase, em termos mais consistentes.

Em prosseguimento, adita-se que ao longo de sua evolução, o homem reuniu herança cultural e genética (VYGOTSKY, 1988, 1987) num conjunto único, tornando possível a assimilação do novo a partir do velho. Em adendo, a metáfora da 'catraca' (TOMASELLO, 2003) propõe uma explicação para o que acontece no ambiente humano, com relação à aprendizagem. Entre os humanos, diz o autor, acontece a acumulação de conhecimentos e não a sua dissipação, porque a transmissão cultural humana se caracteriza, de início, pela reprodução fiel da variante introduzida, permitindo a formação de uma base comum a todos os membros do grupo - uma espécie de plataforma cultural básica. Além disso, Tomasello comenta que apenas entre os integrantes da espécie humana, o imitador coloca-se na pele do outro para executar a atividade inovadora (empatia), exatamente de acordo com o procedimento introduzido por seu criador, sem buscar um método próprio. O que, segundo ele, explica a diferença entre a construção de conhecimento pelos humanos e pelas demais espécies animais.

Explica-se, pois, por que a investigação sobre leitura e produção parafrástica não pode prescindir dos estudos neurocientíficos. Para imitar é preciso ter memorizado e repetido. E para pensar é preciso apropriar-se dos conhecimentos anteriores, bagagem cultural registrada na memória. Além do que, a realidade não se encontra fora do sujeito, pronta, sem qualquer intervenção dele; ao contrário, é preciso interagir com as coisas e pessoas que o rodeiam, para situar-se no mundo físico e humano. Ao interagir, o 
sujeito categoriza o real, para poder entendê-lo e explicá-lo, como afirmam Lakoff e Johnson (2002). Daí decorre que a razão humana não pode ser entendida apenas em termos de manipulação de símbolos abstratos.

Categorizar o mundo demanda organizar de certo modo tudo o que existe, já que o mundo não é a soma de coisas e/ou indivíduos soltos, isolados, mas, sobretudo, de tipos de coisas e indivíduos classificados e ordenados, segundo algum critério, de acordo com a experiência e a imaginação de cada comunidade de falantes (LAKOFF, 1987). A categorização feita depende da existência de alguma convenção preexistente no grupo considerado, uma vez que a categorização é coletiva, já que ninguém pode inventar o que dizer a seu bel-prazer. É necessário haver um consenso inicial. Em suma, é a partir da repetição daquilo que já se sabe (conhecimento prévio), que se dá a renovação do conhecimento.

\section{Palavras finais}

Para concluir, destaca-se um paradoxo flagrante na avaliação da paráfrase, que é tratada apenas como um epifenômeno do ato de ler. Este se refere ao fato de que a leitura é uma atividade reconhecida por todos - pais, professores, pesquisadores, alunos, população, em geral, como essencial para o desenvolvimento humano. Já a paráfrase, texto solicitado para demonstrar a compreensão leitora não goza do mesmo status. Ao mesmo tempo, tem seu valor reconhecido por ser um teste muito efetivo para comprovar o entendimento da leitura feita, mas não é avaliada de forma positiva como produção escrita. $\mathrm{O}$ fato, contudo, é que parafrasear implica tanto testar a compreensão, quanto produzir um texto escrito. E escrever é, sem dúvida, um dos calcanhares de Aquiles do processo de ensino/aprendizagem.

Certamente, não há receitas prontas sobre o que se deve fazer e nem sobre como fazer, para despertar o gosto pela escrita; o que há são indicações. Estas remetem ao exercício continuado, à prática constante desta que, de fato, não é uma atividade fácil, raramente sendo prazerosa para as pessoas que não costumam redigir com frequência. Em vista disso, como uma das estratégias de ensino utilizadas pelos professores dos três níveis de ensino - fundamental, secundário e universitário - é solicitar a produção de paráfrases para verificar se os alunos leram e compreenderam a leitura solicitada, talvez fosse salutar repensar a importância da atividade parafrástica e seu papel no ensino de escrita.

A constância da solicitação de paráfrases (escritas), no meio acadêmico e escolar, é um indicador positivo, sem dúvida. Mas é preciso garantir muito mais do que isso. Faz-se necessário investir mais nessa atividade, acompanhando a evolução dos alunos, também em escrita, via textos parafraseados.

Na ótica de Pinto (2014), é mais do que legítimo se questionar sobre se jovens e adultos (acadêmicos), de modo geral, reagem da mesma maneira frente às duas modalidades de uso da língua (falada e escrita) ou se quando lhes é solicitada a escrita - sobretudo àqueles dentre eles que têm pouca experiência leitora, menor participação em atividades sociais de uso dessa modalidade, menor abertura à aprendizagem ao longo da vida e menor propensão à mudança e à aceitação do novo, a reação seja sempre aversiva.

Assim, se existe alguma possibilidade de enfrentamento das dificuldades de escrita, na certa ela passa pela familiarização com a atividade de parafrasear de modo que fazê-lo se torne um recurso a mais, para exercitar a capacidade comunicativa por escrito. A produção de paráfrases é a possibilidade mais tangível à mão dos professores. Mas não basta o aluno produzir a paráfrase, faz-se necessário receber algum retorno. É preciso interagir através da escrita, discutir pontos de vista, comparar produções. Em suma, a escrita de paráfrases tem de se tornar uma atividade costumeira para poder integrar-se naturalmente à vida do estudante, auxiliando-o a enfrentar suas dificuldades e seus temores de se comunicar por escrito, além de lhe permitir expressar sua interpretação/ compreensão dos textos lidos nas diversas disciplinas curriculares. 


\section{Referências}

ARIMATÉIA, T. S.; CAMPOS, S. F. A paráfrase como ponto de estagnação na escrita acadêmica. 2011. (Apresentação de Trabalho/Comunicação). Disponível em: <http:// www.sigaa.ufrn.br>. Acesso em: 20 maio 2014

BAKTHIN, M. Estética da Criação Verbal. Trad. Maria Ermantina G. Pereira. 3. ed. São Paulo: Martins Fontes, 2000.

DASCAL, M. Interpretação e compreensão. Tradução de Marcia Heloisa Lima da Rocha. São Leopoldo: Unisinos, 2006.

DEHAENE, S. Os neurônios da leitura - como a ciência explica a nossa capacidade de ler. Trad. de Leonor Scliar Cabral. Porto Alegre: Penso, 2012.

DUARTE, P.M. Elementos para o estudo da paráfrase. Revista Letras, Curitiba, n. 59, p. 241-259, jan./jun. 2003

FUCHS, C. A paráfrase linguística: equivalência, sinonímia ou reformulação? Ed. Unicamp, n. 8, p. $129-134,1985$.

FUCHS, C. La paraphrase. Paris: Presses Universitaires de France, 1982.

GAZZANIGA, M.; IVRY, R. B.; MANGUN, G.R. Cognitive Neuroscience - The Biology of the Mind. 2. ed. New York, London: W. W. Norton \& Company, 2002.

ILARI, R.; GERALDI, J. W. Semântica. São Paulo: Ática, 1990.

IZQUIERDO, I. Memória. Porto Alegre: Artes Médicas, 2011.

KINTSCH, W.; VAN DIJK, T. A. Toward a model of text comprehension and production. Psychological Review, v. 85, n. 5, p. 363-394, 1978.

LAKOFF, G. Women, fire, and dangerous things - what categories reveal about the mind. Chicago: The University of Chicago Press, 1987.

LAKOFF, G.; JOHNSON, M. Metáforas da vida cotidiana. Tradução de Mara Sophia Zanotto. São Paulo: Mercado de Letras, 2002.

MARCUSCHI, L. A. Cognição, linguagem e práticas interacionais. Rio de Janeiro: Lucerna, 2007.

MARCUSCHI, L. A. Exercícios de compreensão ou copiação nos manuais de ensino de língua? Em Aberto, Brasília, ano 16, n. 69, jan.-mar. 1996.

PINTO, M. da G. A Prática da Escrita-Composição: um investimento para a vida. Textura, Canoas, ULBRA, v. 16, n. 31. 2014.
PERINI, M.A. Gramática descritiva do português. São Paulo: Ática, 1995. SAEED, John I. Semantics. Oxford: Blackwell, 1997.

SINHA, Ch. Biology, Culture and the Emergence and Elaboration of Symbolization. In: SALEEMI, Anjum P.; BOHN, Ocke-Schwen; GJEDDE, Albert (Eds.). In search of a language for the mind-brain: Can the multiple perspectives be unified? Denmark: Aarhus University Press, 2005.

STERNBERG, R. J. Psicologia cognitiva. Porto Alegre: Artmed, 2000.

TOMASELLO, M. Origens culturais da aquisição do conhecimento humano. Tradução de Claudia Berliner. São Paulo: Martins Fontes, 2003.

VAN DIJK, T. A. Discurso e produção de conhecimento. Trad. de Orison Bandeira Júnior In: BRAIT, B.; SOUZA E. SILVA, M. C. (Orgs.). Texto ou discurso? São Paulo: Contexto, 2012. VAN DIJK, T. A. Cognição: discurso e interação. São Paulo: Contexto, 2010.

VYGOTSKY, L. S. Pensamento e linguagem. Tradução de Jefferson Luiz Camargo. São Paulo: Martins Fontes, 1987.

VAN DIJK, T. A. A formação social da mente - o desenvolvimento dos processos psicológicos superiores. Tradução de José C. Neto, Luís S. M. Barreto e Solange C. Afeche. São Paulo: Martins Fontes, 1988

Recebido em 08/03/2016 Aceito em 27/05/2016. 